\title{
BI-TEXTS IN THE CONTEXT OF NATIONAL-RUSSIAN BILINGUAL EDUCATION
}

\author{
Leila Salekhova ${ }^{1}$ \\ Andrew Danilov ${ }^{2}$ \\ Natalya Spiridonova ${ }^{3}$ \\ Nnamdi Anyameluhor ${ }^{4}$
}

Abstract: This study analyses the problems associated with bilingual teaching mathematics in nationalRussian schools of the Russian Federation. In particular, problems associated with the Russian and Yakut language interference and the mixing of language codes that negatively affect the acquisition of subject knowledge are indicated. Based on the analysis of the speech corpus of bilingual students, the paper revealed the need for the purposeful development of mathematical speech in a primary school. The role of the principle of relying on the native language of schoolchildren in the conditions of bilingual teaching mathematics is determined and the inadmissibility of mixing language codes is justified. The main characteristics of the basic communicative qualities of mathematical speech and the criteria for assessing their level of formation are given. A system of mathematical problems has been developed and presented in the form of parallel textual bodies in two languages (bi-texts) with an indication of the basic communicative qualities of mathematical speech, the development of which they are aimed at. This paper is useful for familiarizing with the potential of bi-texts in a bilingual learning environment. The work shows the process of developing special mathematical problems presented in the form of bi-texts; the presented experience can be applied in the training of other subjects in the conditions of national-Russian bilingualism.

\footnotetext{
${ }^{1}$ Kazan Federal University

${ }^{2}$ Kazan Federal University, Tel. .: +7 (950) 316-01-08.Email: A.V.Danilov@kpfu.ru .

${ }^{3}$ Institute of National Schools in the Republic of Sakha (Yakutia).

${ }^{4}$ Nottingham Trent University (Great Britain).
} 
Keywords: culture of mathematical speech, basic communicative qualities of mathematical speech, bilingual teaching mathematics, mathematical language, code switching, interference, code mixing.

\section{Introduction}

The Federal state standard of basic general school education points out speech development as a necessary component of personal, meta-subject, and subject learning outcomes. This requirement can be projected on studying the subject of mathematics as the need to develop a mathematical language and mathematical speech, as well as the ability to accurately and competently express one's thoughts in oral and written speech as a necessary component of the subject learning outcomes (Federal state educational standard of basic general education, 2019).

The solution to this problem is complicated by the fact that in bilingual educational contexts and linguistically diversified educational audiences, the language of instruction in mathematics is different from the language of thought of most pupils. For the qualitative digestion of educational material during the implementation of basic general education programs in classes with the native (non-Russian) language of teaching, the targeted formation and development of mathematical speech in Russian based on the pupils' native language, becomes relevant. Implementation of a special system of methodological support in the educational process for the development of mathematical speech of schoolchildren in the conditions of national-Russian bilingualism involves the use of special forms, means and methods of bilingual education.

This paper scientifically substantiates and develops a special bitext system of tasks aimed at developing mathematical speech of pupils in the process of bilingual teaching mathematics.

\section{Methods}

According to the results of the previous study (Salekhova \& Spiridonova, 2018), a particularly important stage for bilingual children in their transition to the Russian language of teaching mathematics is the period of $5-6^{\text {th }}$ year of education. A questionnaire which involved 41 primary school 
teachers and subject teachers, including 16 mathematics teachers, showed that the native language is used as the spoken language of pupils, and it is a support for mastering the subject content. Teachers believe that in primary school, it is better to teach children in the language in which they think, that is, in their native language, then gradually switch to Russian as the language of teaching. They also note that their many years of pedagogical experience show a decrease in the need for bilingual pupils to use their native language in the process of studying mathematics at school.

At the beginning of this study, we conducted a stating experiment, the purpose of which was to identify the features of the mathematical speech of bilingual children. We present the results of the study of Yakut-Russian bilingualism based on the analysis of the corpus of mathematical speech for the 5 th grade pupils mastering the program of basic general education in their native and Russian languages. During the study, we observed the process of verbal commenting on the solution of text problems in mathematics in the native and Russian languages. Based on the results of the survey among 27 pupils of the Yakut class, we selected 5 bilingual children whose linguistic portraits coincided according to the following criteria: the age of the pupils, the linguistic characteristics of their parents (in which language they communicate with the child and native speakers), the linguistic characteristics of friends (in which language they speak), a description of the conditions for mastering the native and Russian languages (in a preschool educational institution and school).

A survey of schoolchildren who made a sample of our study showed that, in the bosom of their family, they use their native language in $45 \%$ of cases, and Russian - in 55\%. Parents are representatives of the Sakha people. With friends who are representatives of different nations, they communicate in their native language in $38 \%$ of cases, and in $62 \%$ - in Russian. They also believe that in the primary grades, the share of using the Sakha language during classes in mathematics was $92 \%$, the Russian language $-8 \%$, and in the 5th grade, the native language acts as the language of teaching in $60 \%$ of cases, and the Russian language - 40\%. In preschool educational institutions, they 
attended groups using their native language in the educational process. Pupils answered that they understand the text of the mathematical problems which are compiled in Russian, as they are used to working with the text of tasks from the textbook. We also got to know, that when solving such problems, children think in two languages. The answers of a mathematics teacher with 22 years of teaching experience in the Yakut school indicated that when teaching bilingual children, it is necessary to rely on their native language, especially in 1st-6th grade. The teacher noted that in mathematics he uses his native language in oral speech, for example, when explaining new material, or a method for solving mathematical problems.

\section{Results And Discussion}

Below, we present the results of the experimental study to identify the features of the oral mathematical speech of bilingual schoolchildren in solving standard and non-standard textual problems.

An analysis of the speech corpus of bilingual schoolchildren in the process of solving a standard and nonstandard text problem compiled in
Russian by the number of word usage in their native and Russian languages showed that the Yakut language is the dominant language in both cases, and the second language is Russian. There was a difference in the amount of use of the Russian language (5.16\%) and the manifestations of interference $(1.17 \%)$. We found that in the oral solution of a standard text problem, pupils more often mix language codes when in mathematical speech they unconsciously use the terms and stable phrases available in the text of the problem. In order to comprehend the meaning of mathematical concepts, they consciously switch codes (for example, pronounce a term in two languages, pose a question in one language and answer it in another language). Children prefer to leave untranslated some foreign language inclusions that can be replaced by an equivalent in their native language or pronounce them with deviations from linguistic norms. Such cases of interference when solving a standard problem have been registered by us $1.17 \%$ more often than the cases with solving a non-standard problem. We believe that the reason for the increase in the use of the Russian language and the 
manifestation of interference in solving standard problems is that the method for solving standard problems is contained in the theoretical material presented in the textbook on mathematics. Terms and stable phrases in Russian are introduced into the Yakut speech of bilinguals, due to the fact that they are more convenient, more familiar, or they cannot find the equivalent in their native language. And, on the contrary, since ready-made rules or an algorithm of actions are not spelt out for solving non-standard problems in the textbook, the solution method is derived by schoolchildren independently on the basis of subject knowledge and the application of cognitive techniques.

The results of the analysis for the mathematical speech corpus of bilingual schoolchildren, which is compiled on the basis of their commenting on the process of solving textual mathematical problems, showed that it has specific features. When oral commenting on the decision of textual mathematical problems in Russian, pupils first translate the text of a problem in their native Yakut language and then begin to talk in that language. Bilingual pupils build the grammatical basis of sentences in their native language. At the same time, they mix languages within the framework of one sentence, the terms are often used in Russian (as written in the text of the problem), and the same semantic content is spoken in two languages (they are translated from one language to another). We saw that in solving standard and non-standard problems, the mathematical speech of schoolchildren on the average consists of $88.3 \%$ of the words of their native (Yakut) language and $10.3 \%$ of the Russian language. Therefore, we can conclude that the thinking of bilingual children (Grade 5) proceeds in their native language. Indeed, the need for the purposeful development of mathematical speech in Russian is obvious, especially for pupils in 5th-6th grade.

Language plays an important role in teaching mathematics, not only for transferring mathematical knowledge but also for constructing mathematical knowledge (Maier \& Schweiger, 1999). Some researchers note the importance of integrating subject content and language learning in mathematics, where the development of speech is also the goal of teaching (Wessel, 2015; Farrugia, 2017). There are studies that emphasize the importance of taking into account the 
native language of pupils in the learning process (Cummins, 1981; Cummins, 2000; Clarkson, 1992). According to P.S. Clarkson, when teaching multilingual pupils, it is necessary to take into account the relationship between the language of teaching and the languages that they speak. J. Cummins believes that bilingual pupils learn math better if they are fluent in both languages. As noted by E.M. Vereshchagin, the native language of pupils should be taken into account when selecting the content of training, educational material, its organization and in the educational process itself (Vereshchagin \& Kostomarov, 1990). As the experience of teachers teaching bilingual children shows, the use of the native language as the language of teaching facilitates the assimilation of educational material and helps to overcome conceptual difficulties. We believe that in classes with a native (Yakut) language of teaching, the principle of reliance on the native language should be applied (Shamov, 2008), in addition to general didactic teaching principles.

D.V. Sharmin determines that the concept of "culture of mathematical speech" has two interrelated aspects: 1) a combination of knowledge, skills and abilities that a person or group of people owns and that ensure the optimal use of mathematical language tools in communication; 2) a set of interrelated (communicative) qualities of mathematical speech which evidences about its perfection. By the level of the minimum set of those qualities, one can judge the formation of the culture of mathematical speech in general (Sharmin, 2004).

Knowing that speech is a language in action (Rubinstein, 2002), as well as the components of the mathematical language (word, phrase, symbol, sentence, text) (Ikramov, 1981), we believe that in conditions of nationalRussian bilingualism, the culture of mathematical speech should be formed in two languages.

We have developed a system of special mathematical problems presented in the form of parallel texts (bi-texts), for solving them during mathematics lessons in the conditions of bilingual education.

Let's imagine a system of mathematical problems classified by type of problem and type of speech, 
indicating the communicative qualities of mathematical speech, the development of which they are aimed at.

1. The problems designed to work with the terminology, symbols and graphic images, and aimed at developing the correctness and accuracy of oral and written mathematical speech (explanation of the meaning (or sense) of terms, symbols and symbolic expressions; the transition from the graphic form of the designation to the verbal-symbolic form.

2. The problems designed to work with verbal-logical constructions of a mathematical language and aimed at developing the correctness, logic and accuracy of oral and written mathematical speech.

3. The problems designed to work with written teaching texts and aimed at developing the correctness, consistency, relevance and accuracy of oral and written mathematical speech.

Here is an example of solving the problem for working with verballogical constructions of a mathematical language, namely, finding errors in the definitions of mathematical concepts:

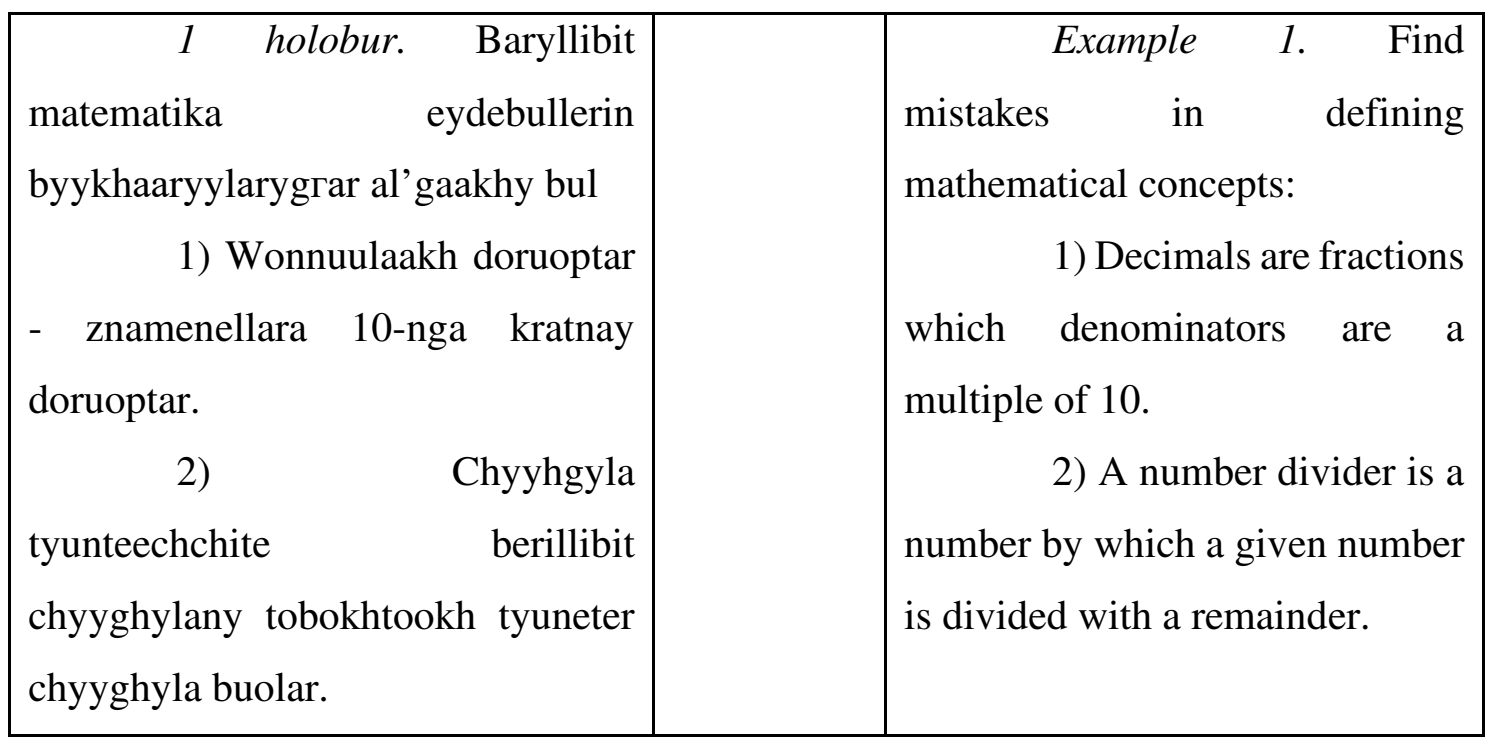

The answers to this problem should be correct from the point of view of mathematics and not violate the norms of the Russian and Yakut languages, and also they should be logically built. When formulating the answer, bilingual pupils 
should consciously switch language codes, and not mix languages. The answer to this problem in the Yakut language can be as follows (eppiette mannyk buoluon syop):

1) Bu bykhaary syykha buolar. 10-n'a kratnay chyyghylalar elbekhter, kholobur, ...- 20, - 10, ..., 20, 30, ... Otton wonnuulaah doruoptar znamenanatellarygar chopchu 10, 100, 1000 ... chyyghylalar tourallar. Onon, wonnuulaakh doruoptar znamenatellara 10-n'ga, 100-ke, 1000$\operatorname{tga}$... ten kratnay doruoptar.

2) Chyyghylany tobokhtookh tyuneter chyyghyla, berilliblit chyyghyla tyuneteechchite buolbat. Onon chyyghyla tyuneteechchite berilliblit chyyghylany tobogoo suokh tyuneter chyyghyla buolar.

The answer in Russian may be as follows:

1) Many numbers can be multiples of 10, for example, - 20, - 10, ..., 20, 30, ...Decimal fractions in the denominator have such numbers as 10 , 100, 1000, etc., which are also a multiple of 10 . Then the mathematical concept of "decimal fractions" can be correctly defined as follows: decimal fractions are fractions which denominators are 10 , 100, 1000, etc.

2) This definition is completely incorrect, since the divisor of a number cannot be the number by which this number is divided with the remainder. Therefore, a number divider is a number by which a given number is entirely divisible, i.e. without a reminder.

\section{Summary}

In the course of our study, we found that the speech-cognitive activity of bilingual children, who were trained and brought up in their native language in a preschool educational institution and in primary school, proceeds mainly in their native language when those children move to a primary school. In this regard, the development of mathematical speech in primary school for pupils in Russian is one of the necessary components of subjectspecific learning outcomes. Under the conditions of national-Russian bilingualism, the culture of mathematical speech should be formed both in the native language and in Russian. For a gradual transition to the Russian language of teaching, it is necessary to take into account the native language of 
pupils, that is, to build a bilingual educational process using the principle of reliance on the native language. We believe that one of the effective means of developing mathematical speech can be a specially developed system of mathematical problems presented in the form of bi-texts mentioned above. Such problems will make it possible to apply the principle of reliance on the native language in mathematics lessons, use the techniques and methods of bilingual learning, control the processes of switching between and mixing language codes, and also avoid the negative effects of language contacts and interference.

\section{Conclusions}

In order to achieve the development of mathematical speech in the conditions of national-Russian bilingualism, it is necessary to control not only the process of use by the pupils of the components of the school mathematical language but also the languages of teaching. To achieve this goal, one of the effective means can be a system of mathematical problems for their solution presented in the form of bitexts.

\section{Acknowledgements}

The work is performed according to the Russian Government Program of Competitive Growth of Kazan Federal University.

\section{References}

Federal state educational standard of basic general education. (2019). Access mode:

http://window.edu.ru/resource/768/7276 8/files/FGOS_OO.pdf (accessed May 28, 2019)

Salekhova, L. L., \& Spiridonova, N. I. (2018). Basic conditions for the development of mathematical speech of schoolchildren in the process of bilingual education. Education and Science, 2(2), 60-87.

Maier, H., \& Schweiger, F. (1999). Mathematik und Sprache [Mathematics and Language]. Vienna: Öbv \& Hpt.

Wessel, L. (2015). Fach- und sprachintegrierte Förderung durch Darstellungsvernetzung und Scaffolding. Ein Entwicklungsforschungsprojekt zum Anteilbegriff [Content and language integrated support by linking 
Periódico do Núcleo de Estudos e Pesquisas sobre Gênero e Direito

Centro de Ciências Jurídicas - Universidade Federal da Paraíba V. 8 - No 07 - Ano 2019 - Special Edition

ISSN | 2179-7137 | http://periodicos.ufpb.br/ojs2/index.php/ged/index

representations and through

scaffolding]. Heidelberg: Springer

Spektrum.

Farrugia, M. T. (2017). Bilingual classrooms in Malta. Teaching mathematics content and language. Éducation et Sociétés Plurilingues 42, $61-72$.

Cummins, J. (1981). The role of primary language development in promoting educational success for language minority students. In California State Department of Education (Eds.), Schooling and language minority students. A theoretical framework (349). Los Angeles: National Dissemination and Assessment Centre.

Cummins, J. (2000). Language. Power and Pedagogy Bilingual Children in the Crossfire. Clevedon: Multilingual Matters.

Clarkson, P. C. (1992). Language and Mathematics. A comparison of bilingual and monolingual students of Mathematics. Educational Studies in Mathematics. Netherlands: Springer Netherlands, 23(4), 417-429.

Vereshchagin, E. M., \& Kostomarov, V. G. (1990). Language and culture: Linguistic and regional studies in the teaching of Russian as a foreign language. - 4th edition, revised and supplemented .M.: Russian language, $57-59$.

Shamov, A. N. (2008). Methods of teaching foreign languages: general course [Study guide] - M.: AST: ASTMoscow: East - West.

Sharmin, D. V. (2004). The formation of a mathematical speech culture by pupils in the process of learning algebra and the principles of analysis: A Methodological Manual. Omsk: Publishing House OmGPU, 52 p.

Rubinstein, S. L. (2002). Fundamentals of General Psychology. St. Petersburg: Peter, 720 p.

Ikramov, J. (1981). Mathematical culture of schoolchildren. Tashkent: Ukituvchi, $280 \mathrm{p}$ 